\title{
A novel rechargeable zinc-air battery with molten salt electrolyte
}

\author{
Shuzhi Liu ${ }^{\mathrm{a}, \mathrm{b}}$, Wei Han ${ }^{\mathrm{a}, \mathrm{b}}$, Baochen Cui*a,b ${ }^{\mathrm{a}}$, Xianjun Liu ${ }^{\mathrm{a}, \mathrm{b}}$, Fulin Zhao ${ }^{\mathrm{a}, \mathrm{b}}$ Jessica Stuart $^{\mathrm{c}}$, and Stuart Licht ${ }^{* \mathrm{c}}$ \\ ${ }^{a}$ College of Chemistry and Chemical Engineering, Northeast Petroleum University, Daqing 163318, China. \\ E-mail:cuibaochen2005@163.com; Tel:+864596504758 \\ ${ }^{b}$ Province Key Laboratory of Oil and Natural Gas Chemical Industry, Northeast Petroleum University, Daqing 163318, China. \\ ${ }^{c}$ Department of Chemistry, George Washington University, Washington DC 20052, USA. \\ E-mail:slicht@gwu.edu;Tel:+1 2029946121
}

\begin{abstract}
Zinc-air batteries have been proposed for EV applications and large-scale electricity storage such as wind and solar power. Although zinc-air ehemistries batteries are very promising, there are numerous technological barriers to overcome. We demonstrate for the first time, a new rechargeable zinc-air battery that utilizes a molten $\mathrm{Li}_{0.87} \mathrm{Na}_{0.63} \mathrm{~K}_{0.50} \mathrm{CO}_{3}$ eutectic electrolyte with added $\mathrm{NaOH}$. Cyclic voltammetry reveals that a reversible deposition/dissolution of zinc occurs in the molten $\mathrm{Li}_{0.87} \mathrm{Na}_{0.63} \mathrm{~K}_{0.50} \mathrm{CO}_{3}$ eutectic. At $550{ }^{\circ} \mathrm{C}$, this zinc-air battery performs with a coulombic efficiency of $96.9 \%$ over 110 cycles, having an average charging potential of $\sim 1.43 \mathrm{~V}$ and discharge potential of $\sim 1.04 \mathrm{~V}$. The zinc-air battery uses cost effective steel and nickel electrodes without the need for any precious metal catalysts. Moreover, the molten salt electrolyte offers advantages over aqueous electrolytes, avoiding the common aqueous alkaline electrolyte issues of hydrogen evolution, Zn dendrite formation, “drying out”, and carbonate precipitation.
\end{abstract}

Keywords: rechargeable zinc-air battery; molten salt electrolyte; zinc deposition/dissolution; air electrode

\section{Introduction}

The growing demands in energy consumption in many aspects of modern life, e.g. electricity usage and transportation, pose challenges to society's capability in maintaining a continuously available energy supply [1]. The widespread emergence of wind, solar and geothermal energy are encouraging and society has been working to establish ways to incorporate these technologies to solve problems caused by the energy crisis. However, these energies are intermittent and not always available. For example, solar energy is available daytime on sunny days but during the night or under cloud-cover rainy days it is unavailable. There is a pressing need to design electrical energy storage systems capable of balancing energy supply with demands [2,3].

Rechargeable metal-air batteries, a relatively new class of batteries, can employ inexpensive metals for electrodes such as nickel for the air electrode and steel, iron or other metals for the counter electrode to achieve high energy densities. High energy density is accomplished by using oxygen from the air (external to the cell) as an active discharge material [4-6]. Recently, Li-air batteries have been attracting worldwide attention for having the highest theoretical energy density, reaching $11680 \mathrm{Wh} / \mathrm{kg}$, almost 30 times higher than that of the Li-ion battery [7,8]. To date, there are many challenges in the development of Li-air batteries, including dendritic charging of the 
anode which can facilitate battery malfunction by shorting, and large overpotentials during the discharge and charge processes, leading to relatively low round-trip energy storage efficiencies [7]. In addition, the limited availability of lithium as a resource, may pose challenges implementation of Li-air batteries for an expanding market to apply to a wide range of applications [9].

Zinc, when compared to lithium, is abundant, less expensive, stable, safer and environmentally benign [10,11]. Among metal-air batteries, zinc-air batteries have received extraordinary attention recently due to their high theoretical specific energy density reaching $1,084 \mathrm{Wh} \cdot \mathrm{kg}^{-1}$ and as the battery generally exhibits a flat, constant discharge voltage [8].

Since the emergence of the zinc-air battery, aqueous electrolytes and predominantly alkaline electrolytes such as $\mathrm{KOH}$ have been adopted based on their low cost, wide availability, and high ionic conductivity as well as other advantages including a low operating temperature [12,13]. Nevertheless, Zn has a more negative reduction potential than hydrogen and can spontaneously generate $\mathrm{H}_{2}$ gas evolution reactions (HER) on the surface of Zn particles in an aqueous medium, deteriorating the efficiency of the $\mathrm{Zn}$ and decreasing the cycle life of the zinc-air battery [14]. The alkaline electrolyte is very sensitive to carbon dioxide when the zinc-air battery is operated in open air and could react with $\mathrm{CO}_{2}$ to form carbonates, causing deterioration of the cell capacity $[15,16]$. Additionally, water evaporation occurring over time as oxygen enters is unavoidable as well as problems with the electrolyte drying out, which result in a shortened battery life [1]. In terms of Zn electrode failure, dendritic growth, shape change, passivation, and self-discharge are the four main problems responsible for poor cycle life performance in aqueous electrolytes [1].

Aqueous electrolyte zinc-air battery investigations are currently principally focused on the development of bifunctional active and durable catalysts to enhance both the oxygen reduction reaction (ORR) for cell discharge and oxygen evolution reaction (OER) for cell charging. Jung and co-workers fabricated a rechargeable zinc-air battery using $\mathrm{La}_{1.7} \mathrm{Sr}_{0.3} \mathrm{NiO}_{4}$ as the bifunctional catalyst. At $25 \mathrm{~mA} \cdot \mathrm{cm}^{-2}$, the battery had an initial discharge voltage of approximately $1.2 \mathrm{~V}$ and charge voltage of approximately $2.0 \mathrm{~V}$ with moderate cycling stability [17]. Prabu and co-workers used $\mathrm{CoMn}_{2} \mathrm{O}_{4}$ nanoparticles supported on $\mathrm{N}$-doped reduced graphene oxide as an electrocatalyst for a rechargeable zinc-air battery. The related zinc-air battery can be reversibly charged/discharged for a hundred cycles with a good cycle performance. The charge-discharge voltage gap $(\Delta \mathrm{V})$ of the catalyst is as small as $0.70 \mathrm{~V}$, which increased to $0.86 \mathrm{~V}$ after 100 cycles at a current density of $20 \mathrm{~mA} \cdot \mathrm{cm}^{-2}$. The round trip efficiency is approximately $54 \%$ at the 100 th cycle (60\% for the 1 st cycle) [18]. Recently, $\mathrm{Li}$ et al. reported a composite catalyst, $\mathrm{Co}_{3} \mathrm{O}_{4}$ 
nanoparticles-decorated carbon nanofibers functioning as an efficient air-cathode in rechargeable Zn-air batteries. The battery exhibits 135 cycles with a round trip efficiency of $61.4 \%$ and a discharge-charge voltage gap of $0.7 \mathrm{~V}$ at $2 \mathrm{~mA} \cdot \mathrm{cm}^{-2}$ under ambient air conditions alkaline aqueous electrolyte of $6 \mathrm{M} \mathrm{KOH} \mathrm{[19].} \mathrm{Park} \mathrm{et} \mathrm{al} \mathrm{introduced} \mathrm{a} \mathrm{hierarchically} \mathrm{porous} \mathrm{and} \mathrm{structurally} \mathrm{robust}$ 3D ordered mesoporous cobalt oxide as a promising air electrode material for electrically rechargeable zinc-air batteries. The related battery displayed a long battery lifetime over 200 cycles without an increasing overpotential measured by voltage difference of $0.76 \mathrm{~V}$ between discharge and charge potential (discharge and charge potential: 1.24 and $2.0 \mathrm{~V}$ ) at $10 \mathrm{~mA} \cdot \mathrm{cm}^{-2}$ [20].

In the past three to four decades, non-aqueous electrolytes such as solid polymer electrolytes (SPEs) and room temperature ionic liquids (RTILs) have been a primary focus to eliminate the previously stated critical problems which are rooted in zinc-air battery aqueous electrolyte systems. SPEs are ionically conductive solids formed by dissolving conducting salt(s) into polymer(s) [21]. One of the major challenges among researchers is to improve the ionic conductivity of SPEs, this is addressed by increasing the fraction of amorphous phase in the polymer [21] or by adding a conducting alkaline, such as $\mathrm{KOH}$ [22]. In the early stages of development, SPEs exhibited extremely low conductivities of $10^{-8}$ to $10^{-7} \mathrm{~S} / \mathrm{cm}$. Ionic conductivities have since been improved to $460 \mathrm{mS} / \mathrm{cm}$, which is comparable to a conventional alkaline aqueous electrolyte [23,24]. However, their reversibility is limited due to the poor buffering property of SPEs for the zincate ion discharge products. This zincate buildup during discharge leads to passivation and limits SPEs in their subsequent charging capabilities. Currently, SPEs are mainly applicable for primary zinc-air batteries rather than secondary zinc-air batteries. On the other hand, RTILs are promising solid electrolyte candidates for rechargeable zinc-air batteries. Compared to conventional alkaline aqueous electrolytes, the exploration of RTIL-based electrolytes shows a wide and stable electrochemical window [25, 26], reduces Zn dendrite formation [27,28], and avoids electrolyte drying out due to it's low volatility [29]. Nevertheless, significant challenges such as reducing viscosity, increasing conductivity, and improving oxygen reduction reaction kinetics remain to achieve viable RTIL based reversible Zn air batteries.

The electrolyte plays a key role in the battery's electrochemistry, which effectively determines rechargeability, cell discharge potential, and the energy it delivers. Therefore, selecting a suitable electrolyte is essential for achieving a breakthrough in battery performance [1]. This study presents the zinc-air molten electrolyte battery, a new addition to the previously reported novel class of rechargeable molten-air batteries, which operate by replacing conventional aqueous electrolytes with a molten $\mathrm{Li}_{0.87} \mathrm{Na}_{0.63} \mathrm{~K}_{0.50} \mathrm{CO}_{3}$ eutectic electrolyte. The prototype zinc-air rechargeable batteries 
constructed using such carbonates eutectic electrolyte exhibited lower overpotential and good cycling stability with high coulombic efficiency.

Here we report the electrochemical performance of this novel battery and mechanisms for discharge/charge reactions. We hope to provide a significant step forward towards solution of the numerous technological challenges facing the existing rechargeable zinc-air battery.

\section{Experimental}

The chemicals and materials utilized for this study are the following: lithium carbonate $\left(\mathrm{Li}_{2} \mathrm{CO}_{3}\right.$, $97 \%)$, sodium carbonate $\left(\mathrm{Na}_{2} \mathrm{CO}_{3}\right.$, anhydrous, $\left.99.8 \%\right)$, potassium carbonate $\left(\mathrm{K}_{2} \mathrm{CO}_{3}\right.$, anhydrous, 99.0\%), sodium hydroxide $(\mathrm{NaOH}, 96 \%)$, zinc oxide $(\mathrm{ZnO}, 99 \%)$, ammonium acetate $\left(\mathrm{NH}_{4} \mathrm{AC}\right.$, 98\%). 2 mm Ni wire ( $99.5 \%$ ), Ni foil (99.95 \%), pure Pt foil (99.999\%), $1.2 \mathrm{~mm}$ Fe wire (Annealed), steel foil (316 steel), and pure alumina crucible (99.7\%).

Cyclic voltammetry (CV) measurements were recorded using an electrochemical workstation (CS350, Wuhan CorrTest instruments Co. Ltd., China). Powder X-ray diffraction (XRD) patterns were resolved by comparison to the library spectra of MDI Jade 5.0 to identify the phases of each sample using a $\mathrm{Cu} \mathrm{K} \alpha$ source (Rigaku D/MAX-2200). Each sample was scanned from $2 \theta 10$ to $80^{\circ}$. Field-emission scanning electron microscopy (FE-SEM, Zeiss Sigma) coupled with energy dispersive spectrometry (EDS, Oxford Instruments X-Max) was employed to determine the morphology and estimate the composition of samples. The samples were prepared for analysis by applying a gold sputtering treatment to the surface.

The cell was situated within a $1800 \mathrm{~W}$ Band Heater, and insulated by rigid thermal shock resistant ceramic insulation containing no binder. The temperature was monitored by a thermocouple and controlled by a temperature controller (708P, YUDIAN automation technology Co. Ltd., China). The charge-discharge behaviors were recorded using a LANHE battery testing system (CT2001A, Wuhan LAND electronics Co. Ltd, China).

\section{Results and analysis}

\subsection{Reversible deposition/dissolution of zinc}

A schematic representation of the zinc molten air battery's charge and discharge processes is presented on the left side of Fig. 1. This battery provides a number of advantages over room temperature zinc-air batteries. With a wide electrochemical window of the molten $\mathrm{Li}_{0.87} \mathrm{Na}_{0.63} \mathrm{~K}_{0.50} \mathrm{CO}_{3}$ eutectic electrolyte (bracketed by carbonate to carbon reduction and oxygen evolution), the electrolyte is electrochemically stable, avoiding the common aqueous alkaline 
electrolyte issue of hydrogen evolution (decomposition of water to $\mathrm{H}_{2}$ and $\mathrm{O}_{2}$ ). Zinc is in a molten state at the operating temperature of $550{ }^{\circ} \mathrm{C}$; hence, there is no dendritic zinc growth, which aqueous zinc air batteries are susceptible to, and which eliminates this short circuits risk. The thermal stability and low vapor pressure of the molten salt electrolyte avoid "drying out of the electrolyte," which is problematic in aqueous air batteries. Finally, the ternary LiNaK carbonates is in a molten state within a wide temperature domain according to the phase diagram of the ternary LiNaK carbonates system [30]. Thus, the carbonates can dissolve in the electrolyte if there are any. This makes them ideal electrolyte useful in preventing carbonate precipitation issues which can occur in alkaline electrolyte batteries. Additionally, a benefit associated with this high temperature cell is that noble metal catalysts are not required for the cell electrochemical oxidation and reduction processes [31]. However, because of the higher operating temperatures, the high temperature batteries in some applications needs thermal insulation, resulting in increase of cell weight (or reducing of energy density), such cells are primarily suitable for large-scale, non-mobile applications such as grid energy storage. Other critical components of these batteries are seals, which must not only be hermetic in high temperature range but also withstand and/or contact with the highly reactive molten cell materials [32]. A further disadvantage is the requirement for electrolyte management, which is necessary to find solutions to some of the electrolyte loss issues by electrolyte migration and electrolyte vaporization, which molten carbonate fuel cell (MCFC) had a similar experience [31, 33].

The melting points of pure lithium carbonate, sodium carbonate, and potassium carbonate are $723{ }^{\circ} \mathrm{C}$, $851{ }^{\circ} \mathrm{C}$, and $891{ }^{\circ} \mathrm{C}$, respectively. However, a eutectic mixture of the three, $\mathrm{Li}_{0.87} \mathrm{Na}_{0.63} \mathrm{~K}_{0.50} \mathrm{CO}_{3}$, melts at $393{ }^{\circ} \mathrm{C}$ thus permitting the study of the zinc-air battery in a low-temperature molten electrolyte domain. In order to consider the electrochemical stability of $\mathrm{Li}_{0.87} \mathrm{Na}_{0.63} \mathrm{~K}_{0.50} \mathrm{CO}_{3}$ eutectic and the potential for reduction of zinc oxide, a thermodynamic evaluation on the zinc-air battery system was carried out. Electrolytic decomposition of lithium carbonate, sodium carbonate, and potassium carbonate $\left(3 \mathrm{M}_{2} \mathrm{CO}_{3}=3 \mathrm{M}_{2} \mathrm{O}+2 \mathrm{CO}_{2}+\mathrm{O}_{2}+\mathrm{C}, \mathrm{M}=\mathrm{Li}, \mathrm{Na}\right.$, $\mathrm{K}$ ) can occur at high temperature $\mathrm{Li}_{0.87} \mathrm{Na}_{0.63} \mathrm{~K}_{0.50} \mathrm{CO}_{3}$ eutectic under applied voltage [34]. The reduction of zinc oxide to zinc is expected in the zinc-air battery. The results of this thermodynamic calculation are shown in Fig. S1 $\dagger$ (†=Supplementary Material) and provide evidence that the potentials for decomposition of the three carbonates are higher than that for the reduction of zinc oxide. For example, the decomposition potential is $1.76 \mathrm{~V}$ for lithium carbonate, $2.58 \mathrm{~V}$ for sodium carbonate, $3.10 \mathrm{~V}$ for potassium carbonate, and $1.37 \mathrm{~V}$ for zinc oxide at $550{ }^{\circ} \mathrm{C}$, respectively. This indicates thermodynamically that zinc oxide should be able to be reduced within the electrochemical window (without electrolytic decomposition) of the carbonate components of the $\mathrm{Li}_{0.87} \mathrm{Na}_{0.63} \mathrm{~K}_{0.50} \mathrm{CO}_{3}$ eutectic electrolyte at $550^{\circ} \mathrm{C}$.

$\mathrm{CV}$ studies of zinc deposition/dissolution were carried out in a molten $\mathrm{Li}_{0.87} \mathrm{Na}_{0.63} \mathrm{~K}_{0.50} \mathrm{CO}_{3}$ 
eutectic containing $3 \mathrm{~m}$ ( $\mathrm{m}=$ molal, moles per kilogram of electrolyte) $\mathrm{NaOH}$ and $1 \mathrm{~m} \mathrm{ZnO}$ at $550^{\circ} \mathrm{C}$. The working electrode was a $0.05 \mathrm{~cm}^{2}$ platinum foil. A $5 \mathrm{~cm}^{2}$ nickel foil electrode was used as the counter electrode and reference electrode. Cyclic voltammetry measurements were recorded in the voltage window ranging from -1.80 to $0 \mathrm{~V}$ at a sweep rate of $100 \mathrm{mV} / \mathrm{sec}$. The voltammograms of the platinum foil electrode during the initial three cycles are shown in the right side of Fig. 1. As evident in Fig. 1, two principal peaks were observed among the three cycles, including the downward reduction peak located at approximately $-1.38 \mathrm{~V}$ which corresponds to the reduction peak of zinc deposition and upward peak at approximately $-0.7 \mathrm{~V}$ for the oxidation of $\mathrm{Zn}$ to $\mathrm{Zn}$ (II).
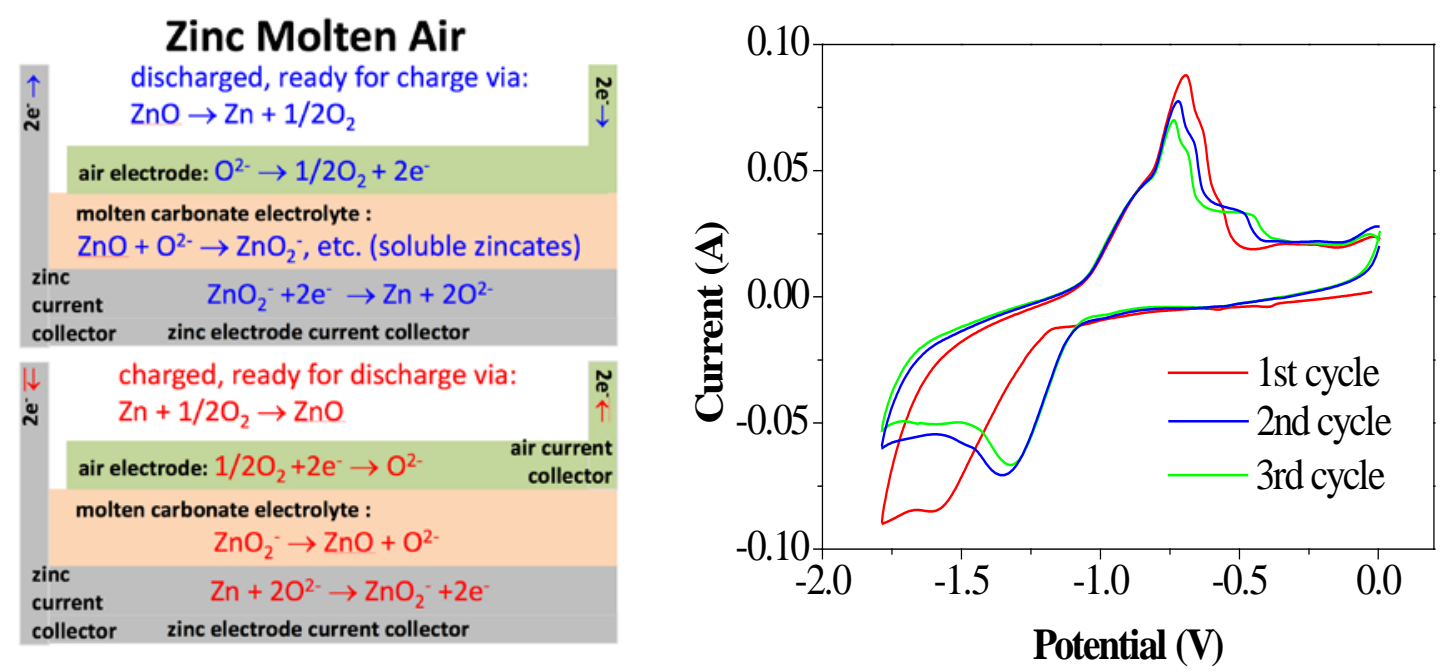

Fig. 1. left: Schematic representation of the zinc molten air battery. right: Cyclic voltammograms in molten $550^{\circ} \mathrm{C}$ $\mathrm{Li}_{0.87} \mathrm{Na}_{0.63} \mathrm{~K}_{0.50} \mathrm{CO}_{3}$ eutectic with $3 \mathrm{~m} \mathrm{NaOH}$ and $1 \mathrm{~m} \mathrm{ZnO}$. Voltage sweep rate: 100mV/sec.

Fig. S2† presents electrolytic zinc deposition (charging) in the molten electrolyte $\mathrm{Li}_{0.87} \mathrm{Na}_{0.63} \mathrm{~K}_{0.50} \mathrm{CO}_{3}$ eutectic with $3 \mathrm{~m} \mathrm{NaOH}$ and $1 \mathrm{~m} \mathrm{ZnO}$ conducted via a constant current electrolysis of $100 \mathrm{~mA}$ at $550{ }^{\circ} \mathrm{C}$. A steel foil $(2 \mathrm{~cm} \times 2.5 \mathrm{~cm})$ cathode and a nickel foil $(2 \mathrm{~cm} \times 2.5 \mathrm{~cm})$ anode were used as electrodes. After completing a 4 hour electrolysis, the cathode (with deposited zinc) was extracted from the electrolyte, cooled, and washed with water to remove the bulk excess electrolyte $\left(\mathrm{Li}_{0.87} \mathrm{Na}_{0.63} \mathrm{~K}_{0.50} \mathrm{CO}_{3}\right.$ and $\left.\mathrm{NaOH}\right)$. The cathode and deposition is then washed using a $15 \% \mathrm{NH}_{4} \mathrm{AC}$ solution for 30 minutes at $80{ }^{\circ} \mathrm{C}$ to dissolve any $\mathrm{ZnO}$ in product. Finally, the cathode with product was flushed with deionized water five times, and then vacuum dried for 30 minutes at $50{ }^{\circ} \mathrm{C}$. The morphology of the prepared cathode and the deposited $\mathrm{Zn}$ was identified and observed using an SEM equipped with EDS analysis. Figs. 2a and 2b display the morphology and zinc distribution of the prepared cathode. As shown in Fig. 2b, zinc particles originating from electrolytic deposition were homogenously dispersed on the cathode. This indicated that Zn (II) in $\mathrm{Li}_{0.87} \mathrm{Na}_{0.63} \mathrm{~K}_{0.50} \mathrm{CO}_{3}$ eutectic could be reduced to zinc. SEM images with lower magnification re 
shown in Figs. 3a and 3b, and most zinc was evenly deposited as particles distributed on the iron foil. The observed deposited zinc particles are elliptical or "drop-like" in character, rather than dendritic or fiber-like. The melting point of pure zinc metal is $419.5^{\circ} \mathrm{C}$; the metallic zinc should be deposited on the cathode surface in the form of liquid drops. After cooling, the liquid zinc drops turn to smooth solid zinc particles. It can be observed from the SEM images with higher magnification in Figs. 3c and 3d, that the size of the zinc particles ranges from 200-400nm.

The above experimental observations are consistent with a reversible deposition/dissolution of zinc in molten $\mathrm{Li}_{0.87} \mathrm{Na}_{0.63} \mathrm{~K}_{0.50} \mathrm{CO}_{3}$ eutectic media, in which the zinc oxide is converted to zinc via a two-electron reduction at the cathode and while $\mathrm{O}_{2}$ is released at the anode. During the discharge process, zinc metal is oxidized to reform zinc oxide using oxygen that is available from the air.

Charging: $\mathrm{ZnO}_{(\text {dissolved) }} \rightarrow \mathrm{Zn}_{(\mathrm{l})}+1 / 2 \mathrm{O}_{2(\mathrm{~g})}$

Discharging: $\mathrm{Zn}_{(\mathrm{l})}+1 / 2 \mathrm{O}_{2(\mathrm{~g})} \rightarrow \mathrm{ZnO}_{\text {(dissolved) }}$
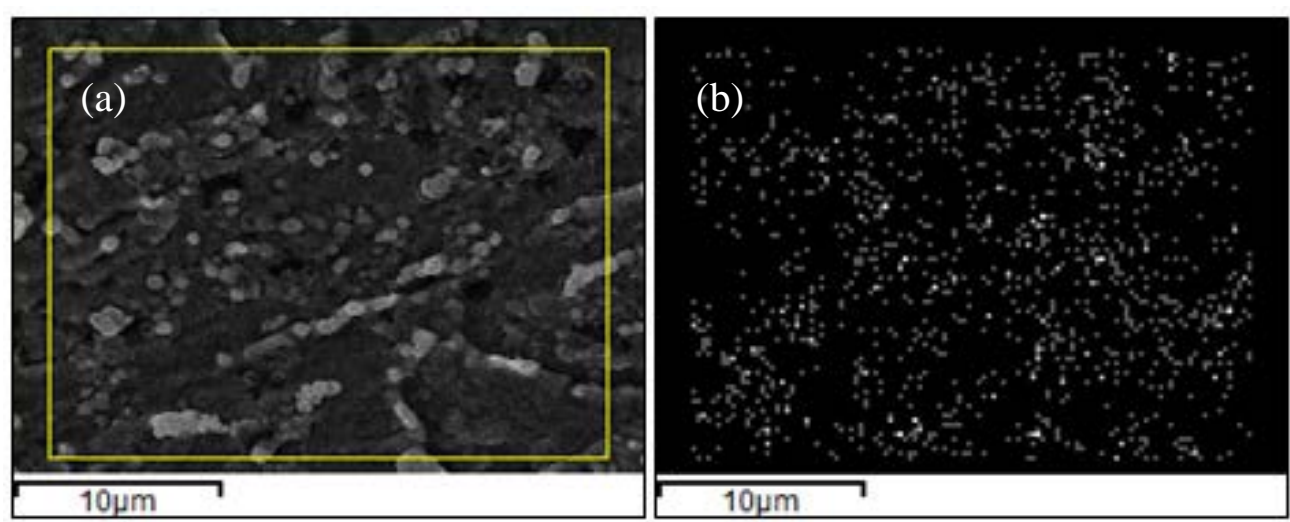

Fig. 2. (a) SEM image of the area of interest within the Zn cathode deposition and (b) the corresponding elemental $\mathrm{Zn}$ maps of the cathodic deposition. 

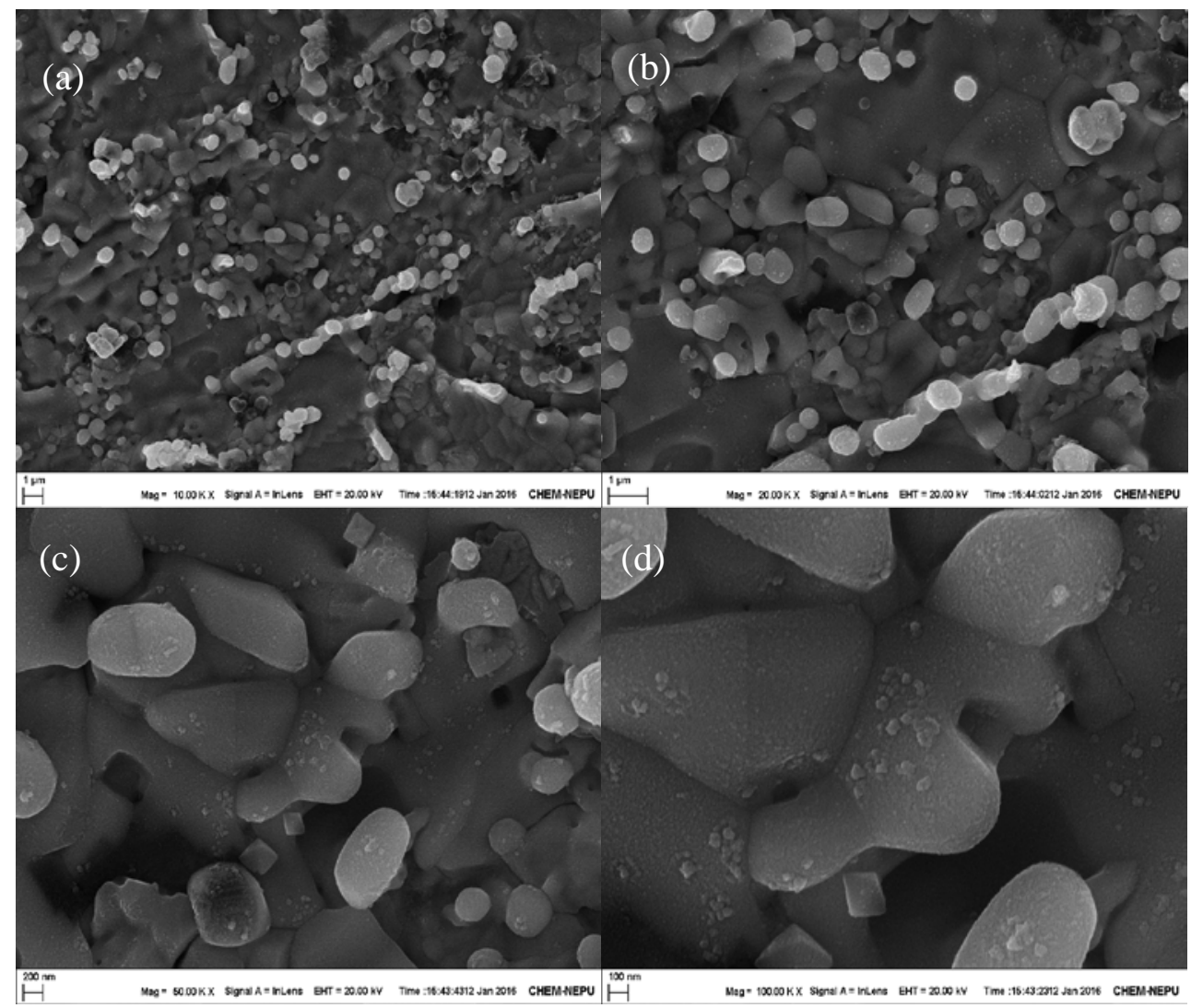

Fig. 3. SEM images Zn cathodic deposition at various magnifications of (a) $10000 \times$, (b) $20000 \times$, (c) 50000×, and (d) $100000 \times$.

\subsection{Characterization of air electrode}

The air electrode was extracted and washed with water to remove the electrolyte after 110 charge-discharge cycles. SEM imaging exhibited no discernable evidence of pitting or corrosion on the surface of the air electrode. XRD patterns of the air electrode are shown in Fig. 4. Compared to the prepared, unused air electrode, XRD analysis of the cycled air electrode exhibits three pure nickel peaks at 2-theta of $44.7^{\circ}, 52.1^{\circ}$, and $76.6^{\circ}$ as well as five other distinct peaks at 2-theta of $37.1^{\circ}, 43.1^{\circ}, 62.6^{\circ}, 75.0^{\circ}$ and $79.3^{\circ}$, respectively, which match the library XRD spectra of $\mathrm{NiO}$ (MDI Jade 5.0, PDF 65-2901). The distribution of NiO, revealed by EDS, shows that the NiO was well dispersed on the used air electrode (Fig. S3†), indicating the formation of $\mathrm{NiO}$ and OER and ORR catalysis nickel oxide during charge-discharge cycling. 


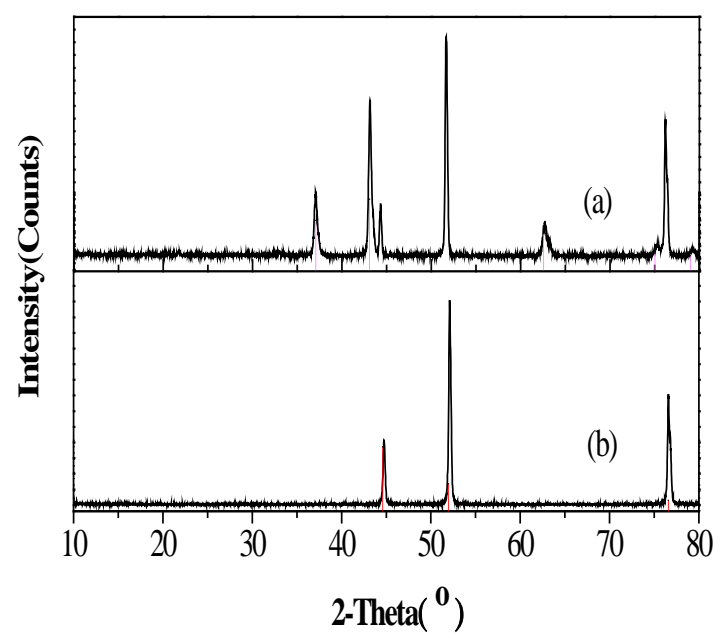

Fig. 4. (a) XRD patterns for the air electrode after cycling (charging and discharging) and washing with water to remove electrolyte. Pink vertical lines: XRD library Nickel Oxide (NiO) spectra PDF: 65-2901, (b) XRD for the fresh air electrode. Red vertical lines: XRD library pure nickel spectra, PDF 70-0989.

The morphology of the air electrode, observed by SEM, is shown in Fig. 5. The electrode surface appears with a range of nano-sized nickel oxide particles which could increase the specific surface area and effectively improve catalytic effects. From the high magnification SEM images, crystal boundaries can be observed for the nickel oxide particles. The particle-size distributions range from 30-200nm.
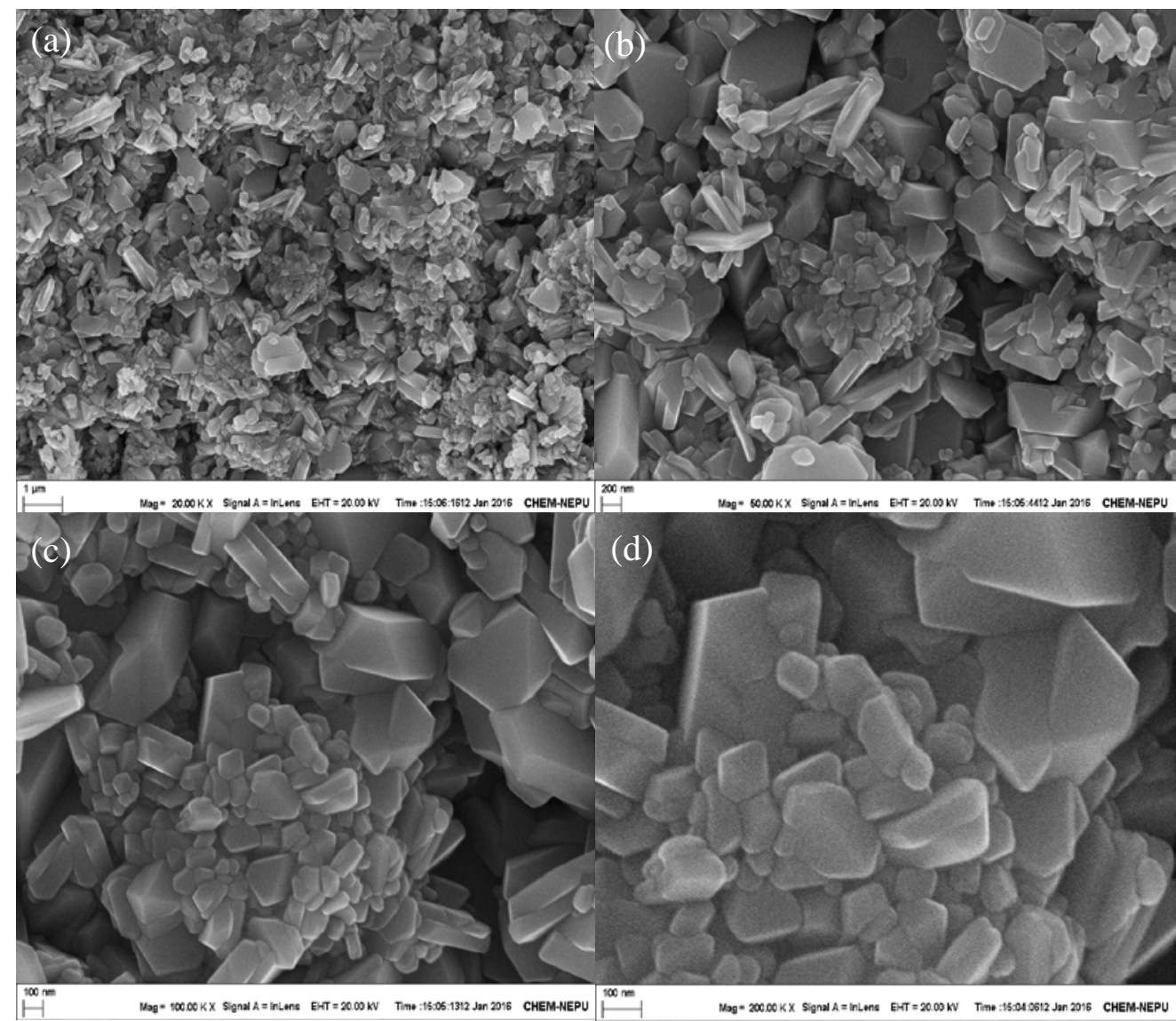
Fig. 5. SEM images for the air electrode after cycling at various magnifications of (a) $20000 \times$, (b) $50000 \times$, (c) $100000 \times$, and (d) 200000×.

\subsection{Cycle performances}

The cycling performance of the zinc-air molten carbonate electrolyte battery was studied by performing charge-discharge cycles consisting of a constant current charge of $0.025 \mathrm{~A}$ for 8 minutes, an open circuit potential measurement over 1 minute, followed by a discharge over a constant load of $100 \Omega$ to a cut-off voltage of $0.8 \mathrm{~V}$. Fig. 6a, presents the characteristic steady cycling over 110 cycles. In Fig. S4†, the indivicual voltage profiles for the $1^{\text {st }}, 30^{\text {th }}, 50^{\text {th }}, 70^{\text {th }}, 90^{\text {th }}$ and $110^{\text {th }}$ cycles are also compared. Each cycle, excluding the initial charge/discharge, exhibits very low hysteresis. As shown in Fig. 6b, the voltage efficiency and the coulombic efficiency for the initial few cycles was between $70 \%$ and $90 \%$. As the charge-discharge cycles continue, both the voltage efficiency and the coulombic efficiency improved (increased and stabilized). After just five cycles, the voltage efficiency increases to around $73.2 \%$, and the coulombic efficiency reaches over $90 \%$, they then continue to fluctuate between $90 \%$ and $97 \%$. The highest coulombic efficiency achieved is $96.9 \%$ in the $24^{\text {th }}$ cycle. We hypothesize that the increase in efficiency is attributed to the in situ oxidation of the air electrode to nickel oxide, during the initial five cycles, which is of high ORR activity. As shown in Fig. 6c, both the average charge and dischage voltages exhibit very stable performances. The average charging potential is $1.43 \mathrm{~V}$, the average open circuit potential is $1.33 \mathrm{~V}$ (close to 1.37 $\mathrm{V}$ of the theoretical potential for reduction of zinc oxide), and the average discharge potential is $1.04 \mathrm{~V}$. The difference between the average charge potential and open circuit potential is approximately $0.1 \mathrm{~V}$, wheras the approximately between the average discharge potential and the open circuit potential is approximately $0.29 \mathrm{~V}$. This results in a high round-trip cycle voltage efficiency of $74 \%$.

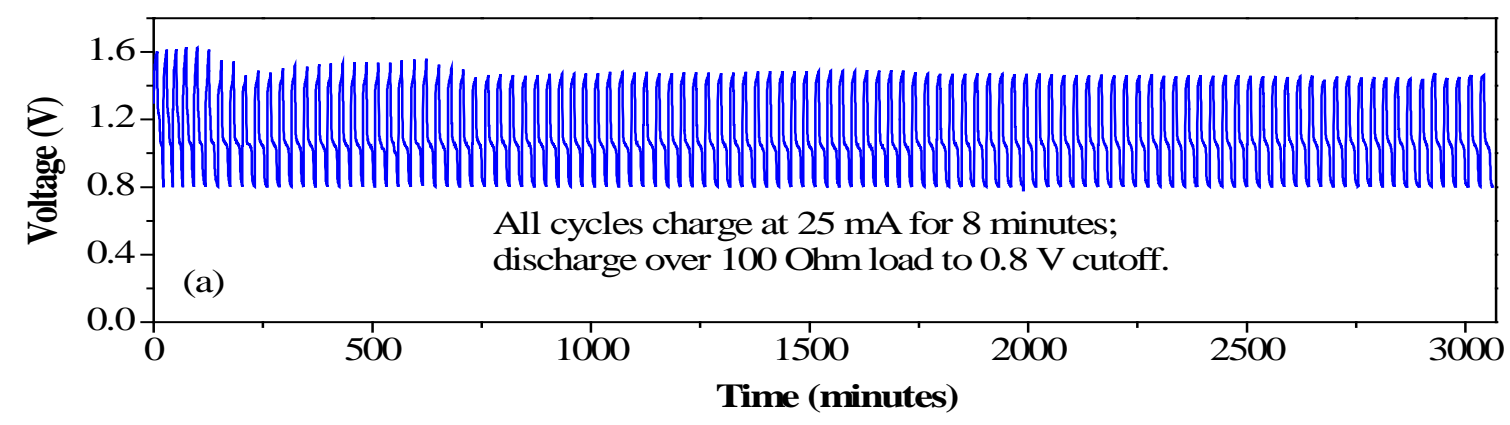



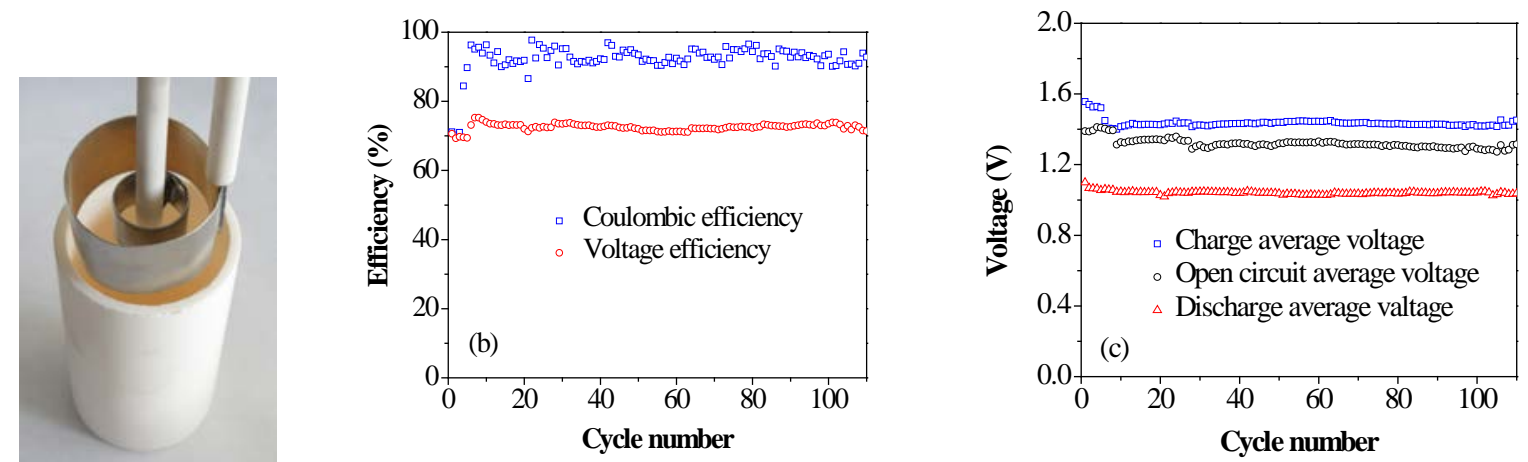

Fig. 6. Cycling (charge-discharge) behavior of the zinc-air battery using molten $\mathrm{Li}_{0.87} \mathrm{Na}_{0.63} \mathrm{~K}_{0.50} \mathrm{CO}_{3}$ eutectic electrolyte with $3 \mathrm{~m} \mathrm{NaOH}$ and $1 \mathrm{~m} \mathrm{ZnO}$ at $550{ }^{\circ} \mathrm{C}$. Left (photo): the battery configuration used a $4 \mathrm{~cm}^{2}$ steel foil $(1 \mathrm{~cm}$ height cylinder with a circumference of $4 \mathrm{~cm}$ ), and a $20 \mathrm{~cm}^{2}$ nickel foil $(2 \mathrm{~cm}$ height cylinder with a circumference of $10 \mathrm{~cm})$ as counter electrode. The steel foil cylinder located concentrically inside the nickel foil cylinder. The molten electrolyte covers the steel foil electrode. The immersed depth of the nickel foil cylinder in the molten salt is $1 \mathrm{~cm}$. Charging is carried out at $0.025 \mathrm{~A}$ for 8 minutes. The battery is discharged over a $100 \Omega$ load to $0.8 \mathrm{~V}$ cutoff. (a) Cycling characteristics. (b) The coulombic efficiency and voltage efficiency. (c) Average voltage of charging, open circuit and discharging.

\section{Conclusion}

The foundation and experimental demonstration of a rechargeable zinc-air battery is established. The zinc-air battery consists of three principal components: a nickel air cathode, a reversible 2-electron zinc anode and a molten $\mathrm{Li}_{0.87} \mathrm{Na}_{0.63} \mathrm{~K}_{0 . \text { ee50 }} \mathrm{CO}_{3}$ eutectic electrolyte with added $\mathrm{NaOH}$. Cyclic voltammetry studies indicate that the deposition-dissolution of zinc is reversible in the electrolyte. EDS, SEM and XRD results indicated that nanostructured nickel oxide particles are formed in situ on the air electrode in the $\mathrm{Li}_{0.87} \mathrm{Na}_{0.63} \mathrm{~K}_{0 . \mathrm{e} 50} \mathrm{CO}_{3}$ eutectic electrolyte. The zinc-air battery shows a stable cycling performance through 110 cycles with a highest coulombic efficiency of $96 \%$, and an average discharge potential of $1.04 \mathrm{~V}$ when charged at a constant current of $0.025 \mathrm{~A}$ and discharged over a constant $100 \Omega$ load to $0.8 \mathrm{~V}$ cutoff at $550{ }^{\circ} \mathrm{C}$.

\section{Acknowledgements}

This work was financially supported by the Natural Science Foundation of Heilongjiang Province, China (Grant No. B2016001). S. Licht is grateful to the Unites States National Science Foundation grant 1505830 for partial support of this study.

\section{Appendix A. Supplementary material}

This work was financially Supplementary material associated with this article is can be found in 
the online version, at http://...

\section{Notes and references}

[1] M. Xu, D.G. Ivey, Z. Xie ,W. Qu, J. Power Sources 283 (2015) 358-371.

[2] B. C. Cui, S. Licht, J. Mater. Chem. A 2 (2014) 10577-10580.

[3] S. Z. Liu, X. Li, B. C. Cui, X. J. Liu, Y. L. Hao, Q. Guo, P. Q. Xu, S. Licht, J. Mater. Chem. A 2 3 (2015) 21039-21043.

[4] V. Neburchilov, H. Wang, J. Martin, Q. Wei, J. Power Sources195 (2010) 1271-1291.

[5] D. Kubo, K. Tadanaga, A. Hayashi, M. Tatsumisago, J. Mater. Chem. A 1 (2013) 6804-6809.

[6] G. Girishkumar, B. Mccloskey, A. Luntz, S. Swanson, W. Wilcke, J. Phys. Chem. Lett. 1 (2010) 2193-2203.

[7] Z. Wang, D. Xu, J. Xu, X. Zhang, Chem. Soc. Rev. 43 (2014) 7746-7786.

[8] J. Lee, T. Sun, R. Cao, N. Choi, M. Liu, K. Lee, J. Cho, Adv. Energy Mater. 1 (2011) 34-50.

[9] Y. Li, H. Y., X. Li, M. N. Banis, R. Li, X. Sun, Chem. Commun. 49 (2013) 11731-11733.

[10] D. Aurbach, Z. Lu, A. Schechter, Y. Gofer, H. Gizbar, R. Turgeman, Y. Cohen, M. Moshkovich, E. Levi, Nature 407 (2000) 724-727.

[11] Y. S. Guo, F. Zhang, J. Yang, F. F. Wang, Y. Nuli, S. I. Hirano, Energy Environ. Sci. 5 (2012) 9100-9106.

[12] P. Sapkota, H. Kim, J. Ind. Eng. Chem. 15 (2009) 445-450.

[13] F. Mclarnon, E. Cairns, J. Electrochem. Soc. 138 (1991) 355-377.

[14] H. Kim, G. Jeong, Y.-U. Kim, J.-H. Kim, C.-M. Park, H.-J. Sohn, Chem. Soc. Rev. 42 (2013) 9011-9034.

[15] L. Jörissen, J. Power Sources 155 (2006) 23-32.

[16] J. Drillet, F. Holzer, T. Kallis, S. Muller, V. Schmidt, Phys. Chem. Chem. Phys. 3 (2001) 368-371.

[17] K.-N. Jung, J.-H. Jung, W. B. Im, S. Yoon, K.-H. Shin, J.-W. Lee, ACS Appl. Mater. Interfaces 5 (2013) 9902-9907.

[18] M. Prabu, P. Ramakrishnan, S. Shanmugam, Electrochem. Commun. 41 (2014) 59-63.

[19] B. Li, X. Ge, F. W. Thomas Goh, T. S. Andy Hor, D. Geng,G. Du, Z. Liu, J. Zhang, X. Liu, Y. Zong, Nanoscale 7 (2015) 1830-1838.

[20] M.G. Park, D. U. Lee, M. H. Seo , Z. P. Cano, Z. Chen, Small 12 (2016) 2707-2714.

[21] C. Berthier, W. Gorecki, M. Minier, M. B. Armand, J. M.Chabagno, P. Rigaud, Solid State Ionics 11 (1983) 91-95.

[22] Z. Zhang, C. Zuo, Z. Liu, Y. Yu, Y. Zuo, Y. Song, J. Power Sources 251 (2014) 470-475. 
[23] B. Wright, V. Peter, Br. Polymer J. 7 (2007) 319-327.

[24] N. Vassal, J. Fauvarque, E. Salmon, Electrochim. Acta 45 (2000) 1527-1532.

[25] M. Bernadette, D. Zhifeng, M. Roger, J. Allen, Langmuir 18 (2002) 1734-1742.

[26] K. Murase, K. Nitta, T. Hirato, Y. Awakura, J. Appl. Electrochem. 31 (2001) 1089-1094.

[27] H. Yamamoto, H. Kinoshita, M. Kimura, H. Shirai, K. Koyama, Electrochem. 74 (2006) 370-373.

[28] T. Simons, A. Torriero, P. Howlett, D. Macfarlane, M. Forsyth, Electrochem. Commun. 18 (2012) 119-122.

[29] M. Deng, P. Chen, I. Sun, Electrochim. Acta 53 (2007) 1931-1938.

[30] A. D. Pelton, C. W. Bale, P. L. Lin, Can. J. Chem. 62 (1984) 457-474.

[31] EG\&G Technical Services, Inc, Fuel cell handbook, seventh ed., Morgantown, West Virginia, USA, 2004.

[32] K. B. Hueso, M. Armand, T. Rojo, Energy Environ. Sci. 6 (2013) 734-749.

[33] K. D. Kreuer, Fuel Cells, Springer Science+Business Media, New York, 2013.

[34] K. Le Van, H. Groult, F. Lantelme, M. Dubois, D. Avignant, A. Tressaud, S. Komaba, N. Kumagai, S. Sigrist, Electrochim. Acta 54 (2009) 4566-4573. 